\title{
Synthesis of Spirocyclic Enones by Rhodium-Catalyzed Dearomatizing Oxidative Annulation of 2-Alkenylphenols with Alkynes and Enynes
}

\author{
Szymon Kujawa, Daniel Best, David J. Burns, and Hon Wai Lam*
}

\begin{abstract}
The dearomatizing oxidative annulation of 2alkenylphenols with alkynes and enynes proceeds with high yields and regioselectivities under $R h(I I I)$ catalysis. These reactions are successful using $\mathrm{Cu}(\mathrm{OAc})_{2}$ or air as the stoichiometric oxidant, and provide spirocyclic enones, the basic ring system of which appears in several natural products. Application of this process to the preparation of a highly functionalized tetracycle is also demonstrated.
\end{abstract}

The heteroatom-directed $\mathrm{C}-\mathrm{H}$ functionalization ${ }^{[}{ }^{1}$ ] of aromatic $\mathrm{C}\left(\mathrm{sp}^{2}\right)-\mathrm{H}$ bonds with alkynes has become a versatile and conceptually attractive approach for the synthesis of a diverse range of heterocyclic compounds. ${ }^{[2-4]} \mathrm{We}$ have recently explored enol-directed catalytic oxidative annulations that provide carbocyclic, rather than heterocyclic products, and have demonstrated the ruthenium-, rhodium-, or palladium-catalyzed formation of spiroindenes from 2-aryl cyclic-1,3-dicarbonyl compounds and alkynes (Scheme 1a). ${ }^{[5]}$ Given the electronic similarity between the enol group of cyclic 1,3-dicarbonyls and the hydroxyl group of phenols, and the broad significance of phenols as chemical building blocks, we became interested in the use of 2-alkenylphenols in dearomatizing oxidative spiroannulations (Scheme 1d). ${ }^{[6]}$ This process would provide spirocyclic enones, the basic ring system of which appears in several natural products (Figure 1). ${ }^{[7]}$

The dearomatization of phenols and naphthols has played an important role in organic synthesis, ${ }^{[8]}$ but has emerged only relatively recently in the context of transition metalcatalyzed $\mathrm{C}-\mathrm{C}$ bond formation. ${ }^{[9,10]}$ Furthermore, until recently, no examples of such transformations initiated by direct $\mathrm{C}-\mathrm{H}$ functionalization of phenol derivatives had been reported. ${ }^{[1]}$ During the early stages of our investigations, Luan and co-workers reported a ruthenium-catalyzed dearomatizing oxidative annulation of 1-aryl-2-naphthols with alkynes (Scheme 1b). ${ }^{[12]}$ Nevertheless, it is important to note that this reaction did not proceed in a synthetically useful yield with phenol-derived substrates. ${ }^{[12]}$ A further indication of the energetic challenges associated with the

[*] S. Kujawa, Dr. D. Best, Dr. D. J. Burns, Prof. H. W. Lam EaStCHEM, School of Chemistry, University of Edinburgh Joseph Black Building, The King's Buildings West Mains Road, Edinburgh, EH9 3JJ (UK) and

School of Chemitry, University of Nottingham University Park, Nottingham, NG7 2RD (UK)

E-mail: hon.lam@nottingham.ac.uk

[**] We thank the ERC, EPSRC, GlaxoSmithKline, and the University of Nottingham for financial support. We are grateful to the EPSRC for a Leadership Fellowship to H.W.L.

Supporting information for this article is available on the WWW.

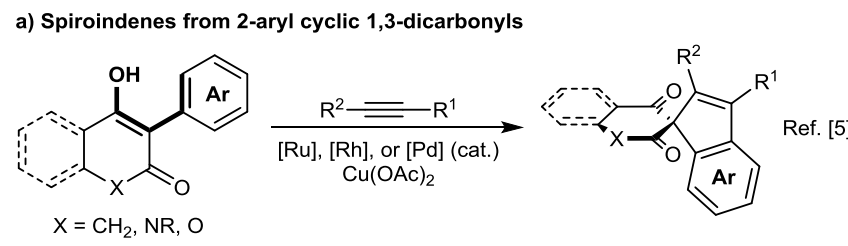

b) Spiroindenes from 1-aryl-2-naphthols

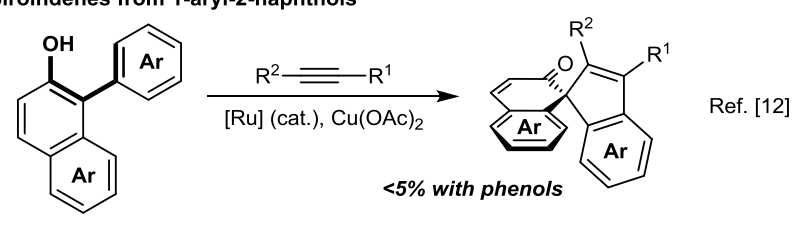

c) Benzoxepines from 2-vinylphenols

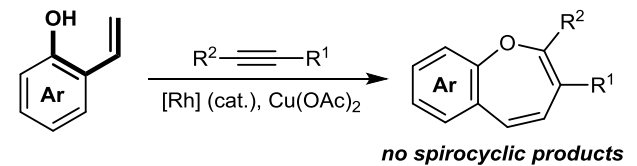

d) This work: spirocyclopentadienes from 2-alkenylphenols

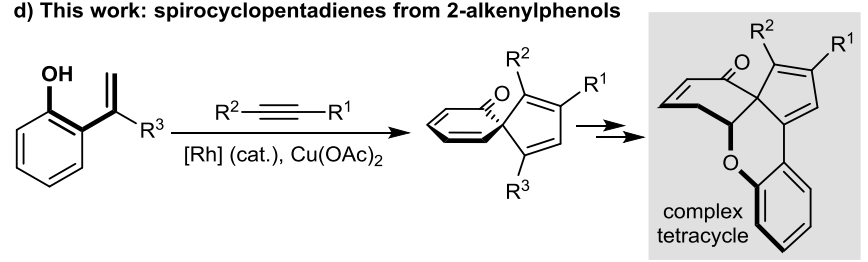

Scheme 1. Oxidative annulations of related substrates with alkynes.

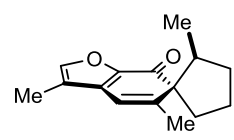

spirovirgafuran

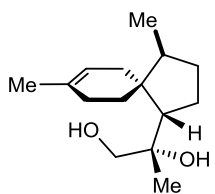

cordycepol B

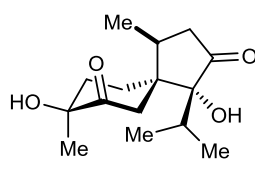

calamusin D
Figure 1. Examples of relevant spirocyclic natural products.

dearomatization of phenols compared to naphthols is evident in recent work from the group of Mascareñas and Gulías, where rhodium-catalyzed oxidative annulation of 2vinylphenol with alkynes provided benzoxepines and not dearomatized products (Scheme 1c). ${ }^{[13]}$ Herein, we report the dearomatizing oxidative annulation of 2-alkenylphenols ${ }^{[14]}$ with alkynes and enynes (Scheme 1d). The presence of a substituent at the 1-position of the alkenyl group is essential for the success of these reactions. Application of this process to the preparation of a complex tetracyclic product is also demonstrated.

Our studies began with the reaction of various 2alkenylphenols with diphenylacetylene using $\mathrm{Cu}(\mathrm{OAc})_{2}(2.1$ equiv) as the stoichiometric oxidant. A brief survey of precatalysts that we previously found to be effective in oxidative spiroannulations with alkynes ${ }^{[5]}$ revealed that only $\left[\left\{\mathrm{Cp}^{*} \mathrm{RhCl}_{2}\right\}_{2}\right]$ exhibited good reactivity. ${ }^{[15]}$ In the case of 
Table 1: Reactions of 2-(1-arylalkenyl)phenols with alkynes. ${ }^{\text {[a] }}$

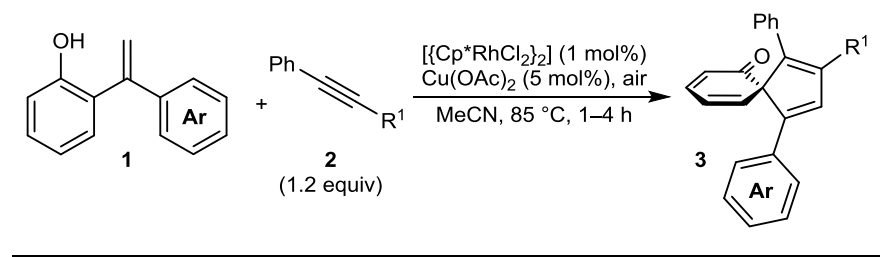

\begin{tabular}{llll}
\hline Entry & Product & Time $[\mathrm{h}]$ & Yield $[\%]^{[\mathrm{b}]}$ \\
\hline
\end{tabular}

1<smiles>c1ccc(-c2cc(-c3ccccc3)c(-c3ccccc3)c(-c3ccccc3)c2)cc1</smiles>

$3 a$

1.5

83

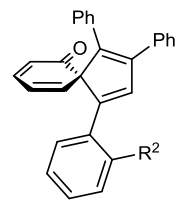

$\begin{array}{ll}\text { 3b } R^{2}=O M e & 3.5 \\ \text { 3c } R^{2}=F & 4\end{array}$

76

84

4

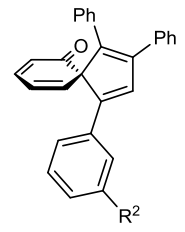

$\begin{array}{ll}\text { 3d } R^{2}=M e & 3 \\ \text { 3e } R^{2}=\mathrm{CF}_{3} & 4\end{array}$

71

6

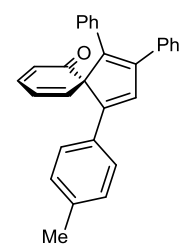

$3 f$

2

70

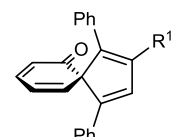

$\begin{array}{ll}3 \mathrm{~g} & \mathrm{R}^{1}=\mathrm{Me} \\ 3 \mathrm{~g} \mathrm{R}^{1}=\mathrm{Me} \\ \text { 3h } \mathrm{R}^{1}=n-\mathrm{Pr}\end{array}$

51 $9^{[d]}$

$\mathrm{Ph}$

76

[a] Using $0.50 \mathrm{mmol}$ of 1 ; >19:1 regioselectivity in all cases. [b] Yield of isolated product. [c] Reaction conducted with [ $\left.\left\{\mathrm{Cp}^{\star} \mathrm{RhCl}_{2}\right\}_{2}\right]$ (2.5 mol\%) and $\mathrm{Cu}(\mathrm{OAc})_{2}$ (20 mol\%) under air. [d] Reaction conducted with $\left[\left\{\mathrm{Cp}^{\star} \mathrm{RhCl}_{2}\right\}_{2}\right](2.5 \mathrm{~mol} \%)$ and $\mathrm{Cu}(\mathrm{OAc})_{2}\left(2.1\right.$ equiv) at $65^{\circ} \mathrm{C}$.

2-vinylphenol, we observed the formation of benzoxepines, a finding that was confirmed by Mascareñas, Gulías, and coworkers shortly thereafter (Scheme 1c). ${ }^{[13]}$ Further exploration revealed that 2-alkenylphenols containing an additional substituent at the 1-position of the alkene provided spirocyclic enones 3 , with no detectable formation of the corresponding benzoxepine (Table 1). Of the solvents tested, acetonitrile was superior to DMF, 1,4-dioxane, and tert-amyl alcohol. Furthermore, it was possible to limit the stoichiometric byproducts to water by performing the reaction with catalytic $\mathrm{Cu}(\mathrm{OAc})_{2} \quad\left(\begin{array}{lll}5 & \mathrm{~mol} \%\end{array}\right)$ and $\left[\left\{\mathrm{Cp}^{*} \mathrm{RhCl}_{2}\right\}_{2}\right](1 \mathrm{~mol} \%)$ under air (balloon) at $85^{\circ} \mathrm{C}$ (bath temperature). ${ }^{[16]}$

Under these conditions, a range of 2-alkenylphenols underwent oxidative annulation with various alkynes (1.2 equiv) to give spirocyclic enones $3 \mathbf{a}-\mathbf{f}$ in $51-84 \%$ yield (Table 1). In addition to 2-(1-phenylvinyl)phenol (Table 1, entry 1), substrates containing substituents of varying electronic character at the ortho- (Table 1, entries 2 and 3), meta- (Table 2, entries 4 and 5), or para-position (Table 1, entry 6) of the non-phenolic aryl group of 1 were tolerated. In all cases, a single regioisomer of the product was detected by NMR analysis of the unpurified reaction mixtures. ${ }^{[17]}$

Next, the scope of the process with respect to the alkyne was examined. The use of 1-phenyl-1-propyne in place of diphenylacetylene in the reaction with 2-(1phenylvinyl)phenol gave spirotetraenone $\mathbf{3 g}$ in only moderate yield using air as the stoichiometric oxidant, even using slightly higher loadings of $\left[\left\{\mathrm{Cp}^{*} \mathrm{RhCl}_{2}\right\}_{2}\right](2.5 \mathrm{~mol} \%)$ and $\mathrm{Cu}(\mathrm{OAc})_{2}(20 \mathrm{~mol} \%)$ (Table 1, entry 7). Alkyl aryl alkynes are less reactive than diaryl alkynes in this process, and under the extended reaction times required for complete consumption of the 2-alkenylphenols, decomposition of the products becomes significant. Nevertheless, greatly improved results can be obtained by using superstoichiometric $\mathrm{Cu}(\mathrm{OAc})_{2}\left(2.1\right.$ equiv) at a lower temperature of $65^{\circ} \mathrm{C}$ (Table 1, entries 8 and 9). Attempted reactions using terminal, trimethylsilyl-substituted, or dialkyl alkynes all resulted in complex mixtures.

However, conjugated enynes $\mathbf{4}$ proved to be excellent substrates for oxidative annulation ${ }^{[18]}$ and provided a range of spirocyclic products $\mathbf{5}$ in high yields with superstoichiometric $\mathrm{Cu}(\mathrm{OAc})_{2}$ (2.1 equiv) at $65{ }^{\circ} \mathrm{C}$ (Scheme 2). Appreciable variation of the alkene component of the enyne is tolerated, with $p$-methylstyryl (5a-e), vinyl (5f), benzyl enoate $(\mathbf{5 g}-\mathbf{j})$, and cyclohexenyl groups $(\mathbf{5 j})^{[19]}$ all giving excellent results with a range of electronically diverse 2-[1(hetero)arylvinyl]phenols. Enynes containing simple alkyl $(\mathbf{5 f}-\mathbf{k})$ and oxygenated alkyl substituents (5a-e) on the alkyne
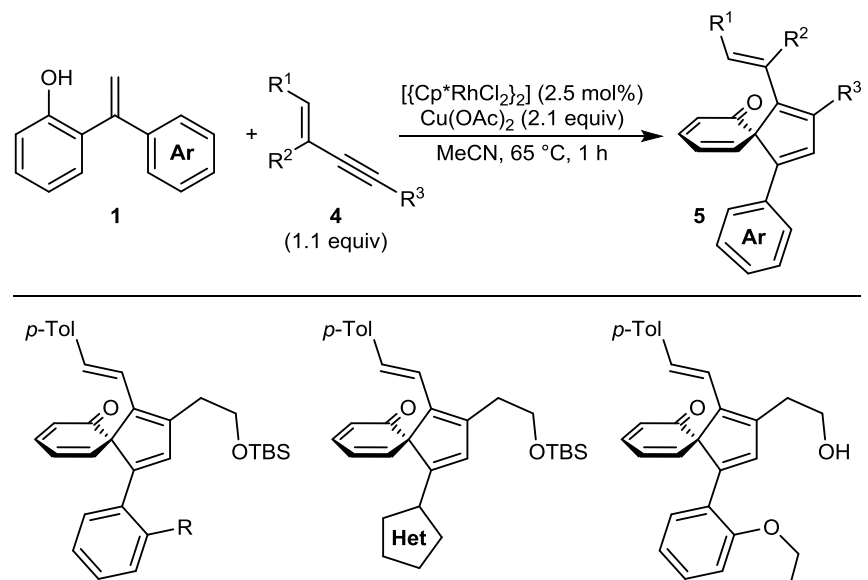

5a $\mathrm{R}=\mathrm{H}, 91 \%$ [a] 5b $\mathrm{R}=\mathrm{Cl}, 89 \%$

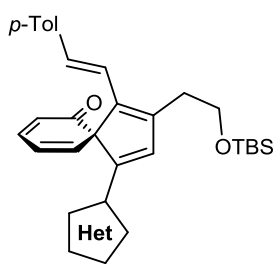

5c Het $=2$-thienyl, $94 \%[\mathrm{a}]$ 5d Het $=3$-thienyl, $92 \%$ [a]
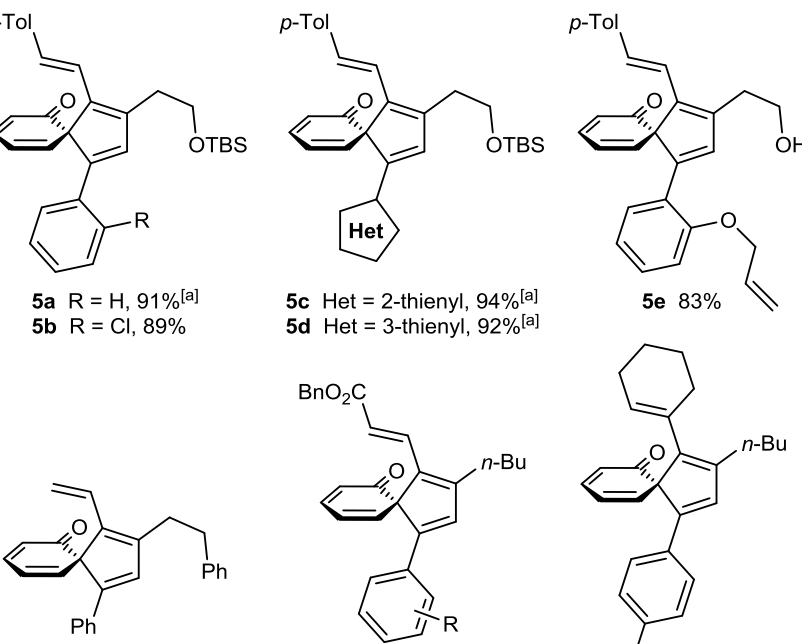

5f $87 \%$
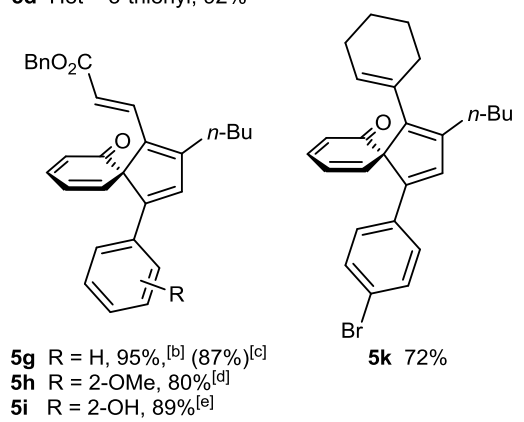

$\begin{aligned} 5 \text { h } \mathrm{R} & =2-\mathrm{OMe}, 80 \%[ \\ 5 \text { i } \mathrm{R} & =2-\mathrm{OH}, 89 \%[\mathrm{e}]\end{aligned}$

5j $\mathrm{R}=3-\mathrm{Cl}, 86 \%$

5k $72 \%$

Scheme 2: Reactions of 2-[1-(hetero)arylalkenyl]phenols with conjugated enynes. Reactions proceeded with $>19: 1$ regioselectivity in all cases. Yields are of isolated single regioisomers. [a] Reaction time was 15 min. [b] Reaction time was 30 min. [c] Reaction conducted with $\mathrm{Cu}(\mathrm{OAc})_{2}(5 \mathrm{~mol} \%)$ under air at $85^{\circ} \mathrm{C}$ for $5 \mathrm{~h}$. [d] Using 1.2 equiv of enyne. [e] Reaction conducted at $40{ }^{\circ} \mathrm{C}$ for $2 \mathrm{~h}$. 
were effective, and an unprotected alcohol (5e) was also compatible. Furthermore, Scheme 2 illustrates the use of 2(1-arylalkenyl)phenols not employed in the examples shown in Table 1, such as those containing 2-chloro (5b), 2allyloxyl (5e), 2-hydroxy (5i), 3-chloro (5j), and 4-bromo substituents (5k). Thienyl-containing substrates were also compatible with this process, despite the potential for catalyst poisoning $(\mathbf{5 c}, \mathbf{d})$. The spiroannulation using enynes was also effective using catalytic $\mathrm{Cu}(\mathrm{OAc})_{2}(5 \mathrm{~mol} \%)$ under air, albeit with a small reduction in yield, as illustrated by the formation of spirocycle 5g in $87 \%$ yield, compared with $95 \%$ yield using the standard conditions using 2.1 equiv of $\mathrm{Cu}(\mathrm{OAc})_{2}$.

The dearomatizing oxidative spiroannulation is not limited to substrates containing a (hetero)aryl substituent at the 1-position of the alkene, as illustrated by the reaction of 2-alkenylphenol 6, which reacted with enyne $\mathbf{4 d}$ to give spirocycle 7 in $82 \%$ yield [Eq. (1)].

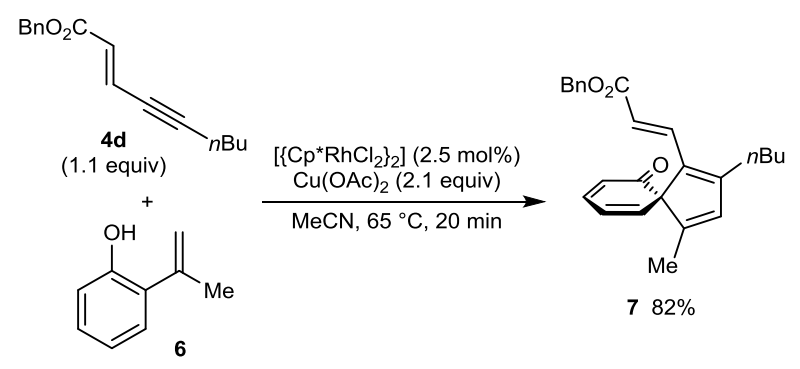

(1)

A possible catalytic cycle for these reactions is presented in Scheme 3. Reaction of $\left[\left\{\mathrm{Cp}^{*} \mathrm{RhCl}_{2}\right\}_{2}\right]$ with $\mathrm{Cu}(\mathrm{OAc})_{2}$ forms the rhodium diacetate complex $\mathbf{8}$, which can then participate in a phenol-directed $\mathrm{C}-\mathrm{H}$ functionalization of the alkene of the substrate $\mathbf{1}$ to generate rhodacycle $\mathbf{9 .}^{[13]}$ Coordination and migratory insertion of the alkyne then provides the rhodacycle 10. When $\mathrm{R}^{1}=\mathrm{H}, \mathrm{C}-\mathrm{O}$ bondforming reductive elimination of $\mathbf{1 0}$ results in benzoxepine 11, as reported previously. ${ }^{[13]}$ In our reactions, where $R^{1} \neq H$, we

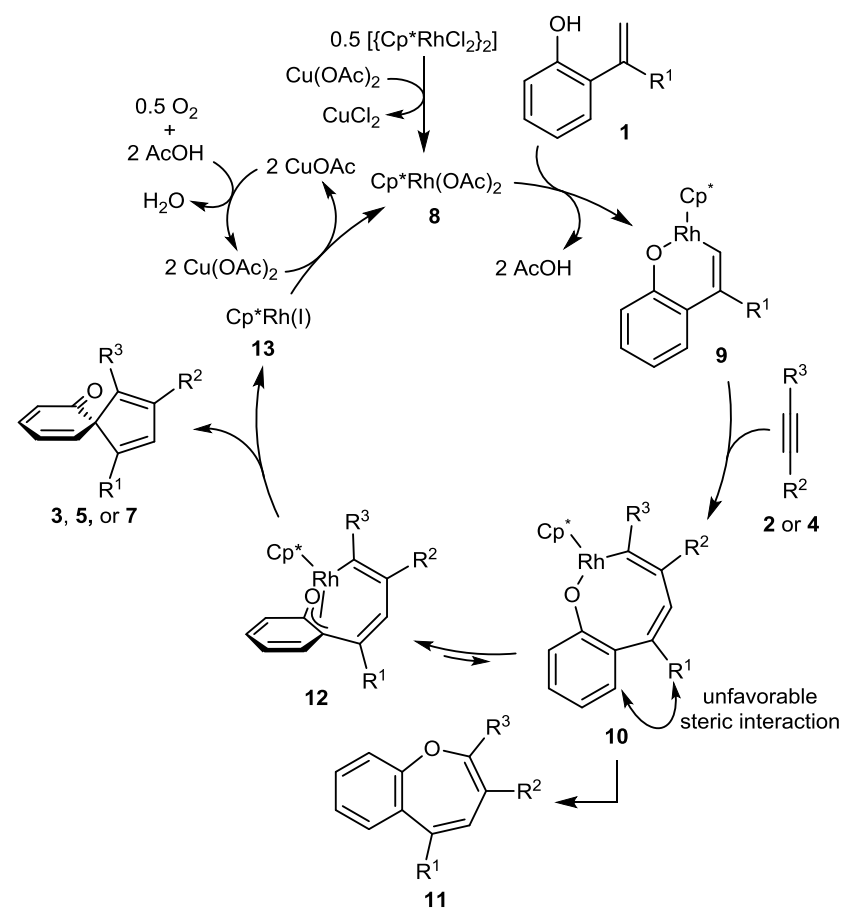

Scheme 3: Possible catalytic cycle. speculate that isomerization of $\mathbf{1 0}$ into rhodacycle $\mathbf{1 2}$ occurs to relieve an unfavorable steric interaction between $\mathrm{R}^{1}$ and the phenoxide ring, despite this isomerization resulting in a decrease in conjugation. A $\mathrm{C}-\mathrm{C}$ bond-forming reductive elimination of $\mathbf{1 2}$ then gives the spirocyclic product $\mathbf{3}, \mathbf{5}$, or $\mathbf{7}$ and $\mathrm{Cp} * \mathrm{Rh}(\mathrm{I})(\mathbf{1 3})$, which can then undergo reoxidation by $\mathrm{Cu}(\mathrm{OAc})_{2}$ to regenerate 8 .

Finally, to demonstrate the further synthetic utility of the products, we exploited the presence of the electrophilic dienone and a nucleophilic phenol in spirocycle 5i. Treatment of 5i with $\mathrm{Et}_{3} \mathrm{~N}$ promoted an intramolecular 1,6-conjugate addition of the phenoxide onto the dienone to give the highly functionalized tetracycle $\mathbf{1 4}$ in $62 \%$ yield, along with recovered starting material in $18 \%$ yield [Eq. (2)].

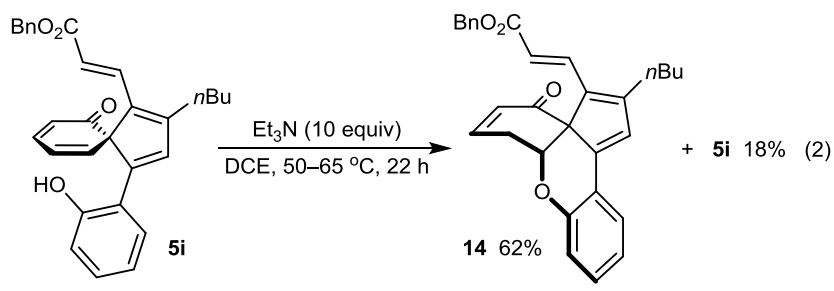

In summary, we have developed a catalytic $\mathrm{C}-\mathrm{H}$ functionalization method for the dearomatizing spiroannulation of 2-alkenylphenols with alkynes and enynes. The process exhibits good generality, leading to highly functionalized spirocyclic compounds in high yields and regioselectivities from relatively simple starting materials. Compared with prior art, ${ }^{[12]}$ the presence of a naphthol in the substrate is not required, and dearomatization occurs with more readily available phenols. The development of enantioselective variants of this process, along with studies into other dearomatizing oxidative annulations, are ongoing in our laboratories.

Received: ((will be filled in by the editorial staff))

Published online on ((will be filled in by the editorial staff))

Keywords: alkyne $\cdot \mathrm{C}-\mathrm{H}$ functionalization $\cdot$ enyne $\cdot$ phenol $\cdot$ rhodium .

[1] For selected reviews covering directing-group-assisted metalcatalyzed C-H functionalizations, see: a) K. M. Engle, J.-Q. Yu, J. Org. Chem. 2013, 78, 8927-8955. b) K. M. Engle, T.-S. Mei, M. Wasa, J.-Q. Yu, Acc. Chem. Res. 2012, 45, 788-802. c) C. S. Yeung, V. M. Dong, Chem. Rev. 2011, 111, 1215-1292. d) J. Wencel-Delord, T. Droege, F. Liu, F. Glorius, Chem. Soc. Rev. 2011, 40, 4740-4761. e) L. Ackermann, Chem. Rev. 2011, 111, 1315-1345. f) C.-L. Sun, B.-J. Li, Z.-J. Shi, Chem. Commun. 2010 46, 677-685. g) T. W. Lyons, M. S. Sanford, Chem. Rev. 2010, 110, 1147-1169. h) D. A. Colby, R. G. Bergman, J. A. Ellman, Chem. Rev. 2010, 110, 624-655.

[2] For a review of rhodium-catalyzed oxidative annulation of alkynes and alkenes, see: T. Satoh, M. Miura, Chem. Eur. J. 2010, $16,11212-11222$.

[3] For a review of ruthenium-catalyzed oxidative annulation of alkynes, see: L. Ackermann, Acc. Chem. Res. 2014, 47, 281-295.

[4] For selected, recent examples of metal-catalyzed oxidative annulations of alkynes, see: a) B. Li, N. Wang, Y. Liang, S. Xu, B Wang, Org. Lett. 2013, 15, 136-139. b) M. Deponti, S. I. Kozhushkov, D. S. Yufit, L. Ackermann, Org. Biomol. Chem. 2013, 11, 142-148. c) L. Wang, L. Ackermann, Org. Lett. 2013, 15, 176-179. d) J. Li, L. Neuville, Org. Lett. 2013, 15, 1752-1755. e) N. Quinones, A. Seoane, R. Garcia-Fandino, J. L. Mascarenas, 
M. Gulias, Chem. Sci. 2013, 4, 2874-2879. f) S. Ding, Y. Yan, N. Jiao, Chem. Commun. 2013, 49, 4250-4252. g) R. Kuram, M. Bhanuchandra, A. K. Sahoo, Angew. Chem., Int. Ed. 2013, 52, 4607-4612. h) M. C. Reddy, R. Manikandan, M. Jeganmohan, Chem. Commun. 2013, 49, 6060-6062. i) K. Muralirajan, C.-H Cheng, Chem. Eur. J. 2013, 19, 6198-6202. j) D. Zhao, Q. Wu, X. Huang, F. Song, T. Lv, J. You, Chem. Eur. J. 2013, 19, 62396244. k) G. Zhang, L. Yang, Y. Wang, Y. Xie, H. Huang, J. Am. Chem. Soc. 2013, 135, 8850-8853. 1) W. Dong, L. Wang, K. Parthasarathy, F. Pan, C. Bolm, Angew. Chem., Int. Ed. 2013, 52, 11573-11576. m) J. R. Huckins, E. A. Bercot, O. R. Thiel, T.-L. Hwang, M. M. Bio, J. Am. Chem. Soc. 2013, 135, 14492-14495. n) M.-N. Zhao, Z.-H. Ren, Y.-Y. Wang, Z.-H. Guan, Org. Lett. 2014, 16, 608-611.

[5] a) S. Reddy Chidipudi, I. Khan, H. W. Lam, Angew. Chem., Int. Ed. 2012, 51, 12115-12119. b) J. D. Dooley, S. Reddy Chidipudi, H. W. Lam, J. Am. Chem. Soc. 2013, 135, 10829-10836.

[6] For a related spiroannulation of hydroxycoumarins with two alkynes, see: S. Peng, T. Gao, S. Sun, Y. Peng, M. Wu, H. Guo, J. Wang, Adv. Synth. Catal. 2014, 356, 319-324.

[7] For an overview of spirosesquiterpenes see: a) A. Srikrishna; M. S. Rao, Ind. J. Chem. 2008, 47B, 1423-1429. For spirovirgafuran, see: b) Y. Saito, Y. Takashima, A. Kamada, Y. Suzuki, M. Suenaga, Y. Okamoto, Y. Matsunaga, R. Hanai, T. Kawahara, X. Gong, M. Tori, C. Kuroda, Tetrahedron 2012, 68, 10011-10029. For cordycepol B, see: c) Y. Sun, Z. Zhao, Q. Feng, Q. Xu, L. Lü, J.-K. Liu, L. Zhang, B. Wu, Y.-Q. Li, Helv. Chim. Acta 2013, 96, 76-84. For calamusin D, see: d) Z.-Y. Hao, D. Liang, H. Luo, Y.F. Liu, G. Ni, Q.-J. Zhang, L. Li, Y.-K. Si, H. Sun, R.-Y. Chen, D.-Q. Yu, J. Nat. Prod. 2012, 75, 1083-1089.

[8] For selected reviews of dearomatization reactions, see: a) S. P. Roche, J. A. Porco, Angew. Chem., Int. Ed. 2011, 50, 4068-4093. b) C.-X. Zhuo, W. Zhang, S.-L. You, Angew. Chem., Int. Ed. 2012 $51,12662-12686$.

[9] For selected examples of the dearomatization of naphthols initiated by transition-metal-catalyzed carbon-carbon bond formation, see: a) A. Rudolph, P. H. Bos, A. Meetsma, A. J. Minnaard, B. L. Feringa, Angew. Chem., Int. Ed. 2011, 50, 58345838. b) T. Oguma, T. Katsuki, J. Am. Chem. Soc. 2012, 134, 20017-20020. c) C.-X. Zhuo, S.-L. You, Angew. Chem., Int. Ed. 2013, 52, 10056-10059.

[10] For selected examples of the dearomatization of phenols by transition-metal-catalyzed, intramolecular carbon-carbon bond formation at the para-position, see: a) T. Nemoto, Y. Ishige, M. Yoshida, Y. Kohno, M. Kanematsu, Y. Hamada, Org. Lett. 2010, 12, 5020-5023. b) Q.-F. Wu, W.-B. Liu, C.-X. Zhuo, Z.-Q. Rong, K.-Y. Ye, S.-L. You, Angew. Chem., Int. Ed. 2011, 50, 4455-4458. c) S. Rousseaux, J. García-Fortanet, M. A. Del Aguila Sanchez, S.
L. Buchwald, J. Am. Chem. Soc. 2011, 133, 9282-9285. d) M. Yoshida, T. Nemoto, Z. Zhao, Y. Ishige, Y. Hamada, Tetrahedron: Asymmetry 2012, 23, 859-866. e) T. Nemoto, Z. Zhao, T. Yokosaka, Y. Suzuki, R. Wu, Y. Hamada, Angew. Chem., Int. Ed. 2013, 52, 2217-2220. f) T. Nemoto, T. Nozaki, M. Yoshida, Y. Hamada, Adv. Synth. Catal. 2013, 355, 2693-2700. g) T. Nemoto, R. Wu, Z. Zhao, T. Yokosaka, Y. Hamada, Tetrahedron 2013, 69, 3403-3409.

[11] Intramolecular ortho-spiroannulation of phenols has been achieved with stoichiometric hypervalent iodine reagents: C. Zheng, L. Wang, J. Li, L. Wang, D. Z. Wang, Org. Lett. 2013, 15, 4046-4049.

[12] J. Nan, Z. Zuo, L. Luo, L. Bai, H. Zheng, Y. Yuan, J. Liu, X. Luan, Y. Wang, J. Am. Chem. Soc. 2013, 135, 17306-17309.

[13] A. Seoane, N. Casanova, N. Quiñones, J. L. Mascareñas, M. Gulías, J. Am. Chem. Soc. 2014, 136, 834-837.

[14] These substrates can themselves be prepared by a $\mathrm{C}-\mathrm{H}$ functionalization approach under Rh catalysis: F. Hu, Y. Xia, F. Ye, Z. Liu, C. Ma, Y. Zhang, J. Wang, Angew. Chem., Int. Ed. 2014, 53, 1364-1367.

[15] PEPPSI-IPr, $\operatorname{Pd}(\mathrm{OAc})_{2}$, and $\left[\left\{\mathrm{RuCl}_{2}(p \text {-cymene })\right\}_{2}\right]$ all failed to provide more than traces of oxidative annulation products in using various 2-alkenylphenols.

[16] No reaction occurred in the absence of either $\left[\left\{\mathrm{Cp}^{*} \mathrm{RhCl}_{2}\right\}_{2}\right]$ or $\mathrm{Cu}(\mathrm{OAc})_{2}$.

[17] The regioselectivities of the reactions were determined by analogy with $\mathbf{5 g}$, the structure of which was confirmed by NOESY NMR analysis, and with $\mathbf{5 k}$, the structure of which was determined by X-ray crystallography. See the Supporting Information for details. The sense of regioselectivity is consistent with transition metalcatalyzed alkyne oxidative annulations reported previously; see Ref. [2-5].

[18] For an example of general application of conjugated enynes in CH functionalization: a) M. P. Huestis, L. Chan, D. R. Stuart, K. Fagnou, Angew. Chem., Int. Ed. 2011, 50, 1338-1341. For other, isolated examples, see: b) L. Ackermann, A. V. Lygin, N. Hofmann, Angew. Chem., Int. Ed. 2011, 50, 6379-6382. c) R. K. Chinnagolla, M. Jeganmohan, Eur. J. Org. Chem. 2012, 2012, 417-423. d) L. Dong, J.-R. Huang, C.-H. Qu, Q.-R. Zhang, W. Zhang, B. Han, C. Peng, Org. Biomol. Chem. 2013, 11, 61426149. e) J.-R. Huang, Q.-R. Zhang, C.-H. Qu, X.-H. Sun, L. Dong, Y.-C. Chen, Org. Lett. 2013, 15, 1878-1881.

[19] The structure of product $\mathbf{5 k}$ was confirmed by $\mathrm{X}$-ray crystallography. CCDC 994371 contains the supplementary crystallographic data for this paper. These data can be obtained free of charge from The Cambridge Crystallographic Data Centre via www.ccdc.cam.ac.uk/data_request/cif. 


\section{C-H Functionalization}

Szymon Kujawa, Daniel Best, David J. Burns, Hon Wai Lam*

Page - Page

Synthesis of Spirocyclic Enones by Rhodium-Catalyzed Dearomatizing

Oxidative Annulation of 2

Alkenylphenols with Alkynes and

Enynes

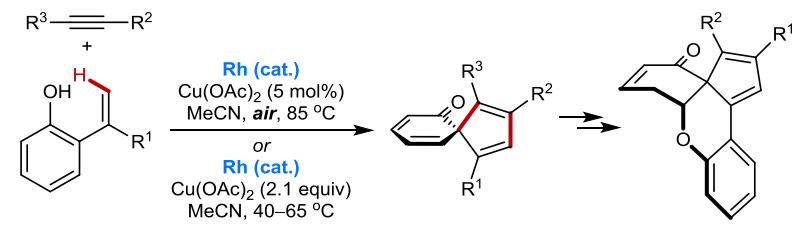

Inspiroing dearomatization: The dearomatizing oxidative annulation of 2alkenylphenols with alkynes and enynes proceeds with high yields and

$\mathrm{Cu}(\mathrm{OAc})_{2}$ or air as the stoichiometric oxidant, and provide spirocyclic enones. Application of this process to the preparation of a highly functionalized regioselectivities under $\mathrm{Rh}(\mathrm{III})$ catalysis. tetracycle is also demonstrated. These reactions are successful using 